\title{
Note on Names and Transliteration
}

As is well known, the practice in Japan of taking pen names ( $g \overline{0})$, especially at the suggestion of friends-and sometimes of changing themwas once common among prose writers. It was also common practice to refer to those writers by this name. Thus Natsume Sōseki rather than Natsume Kinnosuke; Mori Ōgai rather than Mori Rintarō. Indeed, the family name too was often dropped, leaving only the pen name-all that was necessary-to identify the writer. Hasegawa Nyozekan is another case in point. "Nyozekan" is the gō he took early in the twentieth century at the suggestion of a fellow journalist and used for the rest of his life. The meaning, incidentally, is ironic. Taken at a time when Nyozekan was swamped with work, it means "as free and easy as you please." In this book I have followed common practice and refer to "Hasegawa Nyozekan," or, more frequently, to "Nyozekan" alone. In official records and some of his writings, one does find "Hasegawa Manjirō."

Japanese names appear in standard order (family name first), except where the individual has reversed it. This is frequently the case in English-language publications.

Japanese terms, including personal and place names, appear with standard diacritical marks. An exception has been made in the case of well-known place names such as Tokyo, Osaka, and Kobe; and of terms such as Shinto, which is now commonly seen in English.

Chinese names and terms are transliterated in pinyin, except when taken directly from published works where another system is followed. 
